\title{
Lo burlesco en tres poemas coloniales de la Nueva Granada
}

The Burlesque in

Three Colonial Poems

of New Granada

\begin{abstract}
O burlesco em três
O burlesco em três Nova Granada
\end{abstract}

Doctor en Teoría de la Literatura. Docente-investigador, Instituto Caro y Cuervo, $03 \cdot 02 \cdot 2020$ Bogotá, Colombia.

Correo electrónico: guillermo.molina@caroycuervo.gov.co. 


\title{
Resumen
}

La crítica tradicional ha priorizado el estudio de la poesía seria y, dentro de las estéticas de la risa, de la sátira, por sus implicaciones extraliterarias. En este contexto, la poesía burlesca, definida por su juego con la materialidad del lenguaje, constituye una tradición marginal, a pesar de su vitalidad y de sus convergencias con la poesía moderna. El presente artículo de investigación, que toma como punto de partida las categorías establecidas por Alfonso Reyes, analiza tres poemas neogranadinos del siglo XVIII que representan distintas manifestaciones de lo burlesco. Las "Coplas del baile de las brujas" utilizan los recursos de la cultura popular, incluyendo la jitanjáfora, para transmitir una denuncia sociopolítica. La “Felicitación" de Francisco Antonio Rodríguez explora las posibilidades de la polisemia para liberar las palabras de su univocidad, con lo que llega al disparate. Por último, "Para dar días o noches”, de Francisco Javier Caro, evidencia la creación de neologismos por sus resonancias acústicas. En la conclusión se discute el carácter subversivo o acomodaticio de las muestras estudiadas, así como la necesidad de redescubrir la vertiente burlesca del homo ludens en sus producciones literarias.

\section{Palabras clave}

burlesco; jitanjáfora; dislate; cultura popular

\begin{abstract}
Traditional critic has prioritized the study of serious poetry and, to a lesser extent, of satire, due to its extra-literary implications. In this context, burlesque poetry, defined by its game with language materiality, constitutes a marginal tradition, despite its vitality and its convergences with modern poetry. This research paper, based on Alfonso Reyes' theory, analyzes three Colonial Neogrenadian poems representing different possibilities of burlesque. "Coplas del baile de las brujas" uses resources from popular culture, including jitanjáfora, to transmit a socio-political denunciation. “Felicitación”, by Francisco Antonio Rodríguez, explores polysemy to create nonsense verses. Finally, “Para dar días o noches”, by Francisco Javier Caro, creates neologisms to play with acoustic resonances. In the conclusion, we discuss the subversive or accommodative nature of the studied poems, as well as the need to rediscover the burlesque side of homo ludens in the literary productions.

\section{Keywords}

burlesque; jitanjáfora; nonsense; popular culture

A crítica tradicional priorizou o estudo da poesia séria e, dentro da estética do riso, da sátira, devido a suas implicações extra-literárias. Nesse contexto, a poesia burlesca, definida por seu jogo com a materialidade da linguagem, constitui uma tradição marginal, apesar de sua vitalidade e convergência com a poesia moderna. Este artigo de pesquisa, que toma como ponto de partida as categorias estabelecidas por Alfonso Reyes, analisa três poemas neogranadinos do século xvIII que representam diferentes manifestações do burlesco. As “Coplas del baile de las burjas" usam os recursos da cultura popular, incluindo a jitanjáfora, para transmitir uma queixa sociopolítica. “Felicitación”, de Francisco Antonio Rodríguez, explora as possibilidades da polissemia de libertar as palavras de sua univocidade, levando a bobagens. Por fim, “Para dar días o noches", de Francisco Javier Caro, evidencia a criação de neologismos pelas ressonâncias acústicas. Em conclusão, discute-se a natureza subversiva ou acomodativa das amostras estudadas, bem como a necessidade de redescobrir 0 aspecto burlesco do homo ludens nas produções literárias.
\end{abstract}

Abstract

\section{Resumo}

\section{Palavras chave}

burlesco; jitanjáfora; dislate; cultura popular 


\section{Introducción}

En el año 1965, Daniel Samper Pizano se asombraba de haber encontrado lo que él denominó "un De Greiff del siglo xviri". Este poeta, Francisco Antonio Rodríguez (1750-1817), sería, según el crítico, nada menos que "el antecesor - de dos siglos antecesor-de la poesía actual colombiana” (p. 64). Para mostrarlo, compara los juegos con el lenguaje de un poema escrito por el autor colonial con las novedades practicadas en el siglo $\mathrm{xx}$, y concluye que Rodríguez era "no solo raro para su época, sino con muchos puntos comunes con varios de nuestros principales poetas de hoy" (p. 72). Parece que estamos, por lo tanto, ante un verdadero adelantado a su tiempo. Como muestra, copiamos un fragmento del poema elogiado por Samper Pizano, "Felicitación":

[...] y ser discreto es cierto que no espero,

a menos que en el Sacro Orden Tercero

título se me dé; mas, ¿qué me admiro si disparo

tal vez y tal deliro?

(Citado en Vergara y Vergara, 1958, p. 97).

En efecto, los versos de Rodríguez pueden parecer sorprendentes en el contexto de la poesía colonial de la Nueva Granada, e incluso de todo el continente, puesto que lo más habitual en la ciudad letrada era la escritura de poemas guiados por un contenido extraliterario, fuera este de naturaleza laudatoria, religiosa, descriptiva, amorosa o incluso satírica. En este fragmento, sin embargo, el juego desenfadado con las palabras se sitúa por encima de la transmisión de cualquier mensaje (de forma explícita, se celebra el delirio sobre la discreción). La libertad extrema con la lengua suele estar asociada a las vanguardias del siglo $\mathrm{xx}$, establecidas en ocasiones como mito fundacional de la poesía contemporánea. De este acercamiento proviene la consideración de Rodríguez como un olvidado precursor de la modernidad. ${ }^{1}$

1 La relación entre la poesía burlesca y las prácticas de la poesía vanguardista (y, en general, de la moderna) no pasaron desapercibidas para los propios creadores, como muestra el caso de Paul Éluard, quien conecta el género burlesco de la fatrasie con la revolución surrealista.
Una visión más amplia, sin embargo, revela que las conclusiones de Samper Pizano, aunque de gran interés, deben matizarse. La simple escucha de algunos juegos infantiles hubiera bastado para relativizar la novedad de los vanguardistas y de su supuesto precursor. También, un conocimiento más profundo de la historia de la poesía hispánica, en la que no han faltado juegos similares con el lenguaje, desde la Edad Media hasta nuestros días (Juan del Encina, Tirso de Molina, Quevedo, Juana Inés de Asbaje, etc.). Una tendencia que, por cierto, la lengua española comparte con muchas otras, en diversos espacios culturales y épocas: como muestra, valga el estudio de Martínez Pérez sobre la poesía medieval francesa de ámbito popular y, por otro lado, las conocidas variantes del "nonsense" en la escritura de Edward Lear y Lewis Carroll, en la Inglaterra victoriana. Incluso, nos arriesgamos a pensar que el uso burlesco del lenguaje, en cuanto explotación de su materialidad significante, podría llegar a documentarse en todas las lenguas, aunque sea distinta la interpretación ofrecida desde las diversas culturas (mientras que la visión occidental actual lo entiende como simple juego, otros sistemas de pensamiento pueden asignarles a estas producciones efectos mágicos).

El reduccionismo de Samper Pizano, hombre de extensa cultura, es comprensible, y posiblemente podría repetirlo la crítica cincuenta años después. ${ }^{2}$ El canon de la poesía hispana ha primado tradicionalmente el ámbito de la seriedad "racional", lo que genera un desconocimiento de la risa. Tampoco este sesgo es exclusivo del ámbito hispano o anglófono. La citada Martínez Pérez, para el caso francés, afirma que

[...] a pesar de la amplia tradición francesa de poesía irracional, pocos han sido los estudios que han abordado este tema con cierta profundidad [...]. Por el contrario, las críticas, e incluso el desprecio, hacia la poesía del non-sens han sido muy abundantes. $(1987$, p. 7).

2 Algo similar le sucedió a George Orwell cuando afirmaba que “Edward Lear fue uno de los primeros escritores en manejar la fantasía pura, países imaginarios y palabras inventadas sin propósito satírico alguno" (2016, p. 193). 
En Occidente, según vemos, el canon ha primado en las obras serias de las que puede extraerse algún tipo de conclusión moral directa.

Incluso cuando los académicos se acercan a este ámbito, como ha sucedido en las últimas décadas con la sátira colonial, lo hacen para buscar la manifestación de algún conflicto sociopolítico. Como afirma Lasarte (2009), "la historia literaria se ha preocupado mayormente por sus antecedentes clásicos y didácticos, pasando por alto el debido reconocimiento de una importante herencia literaria que relativiza el didactismo a favor de la risa y el juego intrascendente" (p. 268). Este descuido es especialmente sorprendente si tenemos en cuenta que, al menos en España, la literatura festiva fue profusamente cultivada en la época clásica, y que sus mejores obras, como el propio Quijote, se relacionan con esta tendencia (Cacho Casal, 2007, p. 21). Bien es cierto que en la cultura escrita de la Nueva Granada, como luego explicaremos, la risa tuvo un papel menos destacado, pero pudo sobrevivir en obras de inspiración popular y/o producida en contextos informales.

Antes de entrar en materia, es necesario definir nuestro objeto de estudio, que ha tenido una multiplicidad de rótulos a lo largo del tiempo (poesía jocosa, festiva, cómica, etc.). Para ello, recurrimos a dos términos que Arellano (2006) distingue como extremos de un mismo espectro: lo satírico, definido por su intención moral (la corrección de vicios); y lo burlesco, que estaría ligado al estilo (al juego con la materia del lenguaje). De sus posibles cruces surgen tres modalidades: poemas satíricos no burlescos, poemas satíricos burlescos y poemas burlescos no satíricos, "atentos únicamente al delectare y a la diversión risible que procede del alarde estilístico" (pp. 340-341). Será esta última categoría de la que nos ocuparemos en el artículo, aunque en ocasiones incursionaremos también en el terreno de lo satírico.

Lo burlesco, por lo tanto, se fundamenta en el juego con la materialidad del lenguaje. En este sentido, guarda cierto paralelismo con la comicidad in dictum que teorizaban los tratadistas grecolatinos (como Cicerón en De oratore) en oposición a la comicidad por el asunto o situación (in re). De forma análoga, lo burlesco se puede asociar a lo que Ynduráin (1974) denomina función lúdica del lenguaje, que identifica en aquellas obras o fragmentos cuyo contenido es "prácticamente nulo" (p. 365). Por cierto, no deja de ser dicente que el estudioso español tuviera que proponer la adición de esta función por su olvido en el listado clásico de Roman Jakobson.

Con el objetivo de profundizar más en este campo, tomaremos como punto de partida al mexicano Alfonso Reyes, quien, en nuestra opinión, sigue siendo la principal referencia teórica para el mundo hispano. Es necesario recordar que, para denominar lo burlesco, Reyes adoptó el término jitanjáfora del poeta cubano Mariano Brull. Aunque usualmente se asocia la jitanjáfora a la creación de palabras sin referente conceptual, lo cierto es que el teórico mexicano usaba este término de una manera mucho más amplia, como comprobaremos de inmediato. En primer lugar, Reyes (2011) distingue dos "familias" de jitanjáforas. Por un lado, la candorosa, de carácter popular y muchas veces pueril, que suele ser acompañada por una melodía. Pensemos en las rimas infantiles, como la siguiente recogida en Colombia por Otero Muñoz (1928):

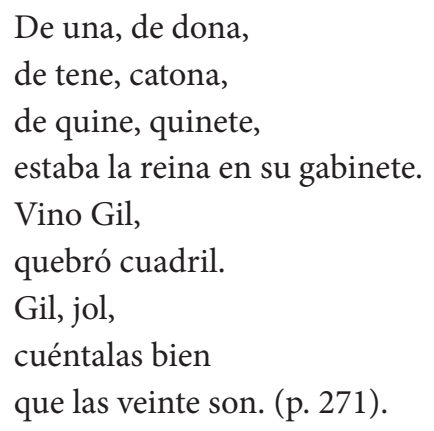

Por otro lado, se sitúa la jitanjáfora conscientemente alocada, que es la que practican los autores cultos. Dentro de este segundo grupo, Reyes establece dos "grados": "el primero es un dislate culto, respetuoso de la gramática y solo absurdo en cuanto a los anacronismos y a las relaciones intelectuales inverosímiles", lo que "hace pensar en el letrado"; y el segundo, que "extrema la fantasía, tuerce la lengua y aun la inventa, 
juega como el pueblo con los valores acústicos sin sentidos", lo que "hace pensar en el poeta" (p. 39). En ambos casos, se trata de poemas escritos en los que el autor juega con las palabras, bien sea con los significados (dislate culto), bien sea con los significantes (extrema fantasía). Por supuesto, es difícil pensar en poemas que se puedan encuadrar exclusivamente en una de las categorías: más bien, proponemos pensar en ellas como los polos del espectro burlesco (que, a su vez, funciona - en su conjunto- como extremo complementario del satírico ${ }^{3}$ ).

En nuestro estudio, utilizaremos esta clasificación trimembre (carácter popular, dislate culto y extrema fantasía) para el análisis de tres poemas que consideramos cercanos a las categorías mencionadas. Se trata de tres piezas de mediana longitud (entre los 124 y los 200 versos), producidas en un mismo contexto: la Nueva Granada del siglo XVIII. De esta manera, queremos subrayar la coexistencia de las tres tendencias y, al mismo tiempo, la diversidad de posibilidades (no ligadas, por lo tanto, a una sucesión cronológica).

La primera de estas obras es "Coplas del baile de las brujas", de autor desconocido, seguramente a causa del fuerte contenido crítico. Está fechada en el año 1717, fue rescatada a finales del siglo XIX por José Manuel Groot, como apéndice de su Historia eclesiástica y civil de Nueva Granada, y posteriormente publicada por Pacheco Quintero, de quien la tomamos. El siguiente poema, al que se refería Samper Pizano en el mencionado estudio, es la "Felicitación" de Francisco Antonio Rodríguez, obra manuscrita que salvó del olvido Vergara y Vergara en su Historia de la literatura en Nueva Granada. En este mismo repertorio encontramos el tercero de los poemas seleccionados, "Para dar días o noches", escrito por Francisco Javier Caro (1750 -1822), autor contemporáneo de Rodríguez, y tronco de la famosa rama de los Caro en Colombia.

3 Parece claro que la poesía de carácter popular también podría clasificarse dentro del espectro burlesco que acabamos de proponer (es decir, produc ciones más próximas al juego con los significantes 0 al absurdo de los significados). Sin embargo, creemos que es conveniente mantener la especificidad de los discursos populares, que utilizan recursos propios de gran relevancia, como la oralidad y, en el caso de la poesía, el acompañamiento melódico.

\section{Lo burlesco de inspiración popular: "Coplas del baile de las brujas"}

Como mencionábamos, es bastante sencillo encontrar ejemplos de jitanjáforas populares en los juegos infantiles. Una de estas canciones dio origen al conocido poema de José Asunción Silva que comienza, precisamente, “¡Aserrín! ¡Aserrán! Los maderos de San Juan". El empleo fructífero de la jitanjáfora no se agota en este tipo de obras, sino que se extiende, según nos recuerda Alfonso Reyes, hasta las canciones de cuna, estrofas bobas, gritos de guerra, porras deportivas, etc. Y, lo que resulta más interesante en nuestro caso, las canciones de brujas.

El caso de las "Coplas del baile de las brujas" (1717), sin embargo, no se puede atribuir automáticamente a la tradición popular. Ciertamente, es una tarea compleja establecer los límites de lo popular: baste aquí definirlo en oposición a lo culto, es decir, a las producciones escritas de la ciudad letrada. Si bien, como veremos, la forma de las coplas se inspira en las citadas canciones de brujas, el contenido parece alejado de las preocupaciones de las clases populares. De hecho, el poema surge de un conflicto entre dos bandos de la alta burocracia colonial: por un lado, los oidores, a quienes se critica con nombres propios; por el otro, los letrados cercanos al presidente de la Audiencia de Santafé de Bogotá, Francisco Meneses Bravo de Saravia, que había sido depuesto y deportado a España.

En este contexto, la elección de una forma popular, asociada a una tonada reconocible, puede entenderse como una estrategia que permite tanto el ocultamiento del autor (situado, muy posiblemente, en el bando perdedor de la contienda) como la transmisión oral del poema, en una época en que la imprenta todavía no había llegado a la Nueva Granada. De esta forma, el poema neogranadino se inserta en una tradición disidente que, en el mundo hispánico, está representada por obras anónimas como las Coplas del Provincial o las de Mingo Revulgo, con las que podría trazarse una fructífera comparación.

El procedimiento compositivo de las "Coplas del baile de las brujas" queda en evidencia desde la primera cuarteta, en la que el coro repite unos versos 
directamente extraídos de la tradición. Estos versos están asociados al cuento Domingo siete, en el que, precisamente, se censura la codicia (atributo del que se acusa a los enemigos):

Lunes y martes

Y miércoles tres,

Jueves y viernes

Y sábado seis.

(Citado en Pacheco Quintero, 1970, p. 437).

El resto de las coplas seguirá la misma estructura de versos pentasílabos y hexasílabos con rima asonante, en "é", en los versos pares. Este hecho nos lleva a pensar que todas las estrofas se cantaban con la misma melodía, lo que supone el aprovechamiento estratégico de una tonada consolidada por la tradición popular (la de Domingo siete). La continuación del ritmo resulta muy evidente en la segunda estrofa, en la que simplemente se sustituyen los días de la semana por los nombres de los oidores vilipendiados:

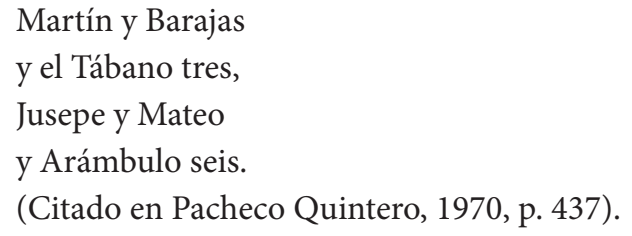

Centrándonos ya en nuestro tema, lo interesante de estos últimos versos es la conversión de una estrofa de jitanjáfora (el conteo de los días de la semana) en una estrofa informativa en que se introducen los nombres de los sujetos que a continuación serán, uno por uno, atacados. Curiosamente, si tenemos en cuenta nuestro contexto de recepción, se trataría de un proceso de ida y vuelta: hoy en día, de estos nombres solo queda la sonoridad. Es posible que sucediera lo mismo con muchos de los habitantes de la Santafé dieciochesca que repetían estas coplas, si es que llegaron a tener tal aceptación popular.

Todo el poema se articula en torno a una tensión entre dos marcos de referencia muy distintos: por un lado, el tiempo mítico de las canciones de brujas, en cuyo contexto las jitanjáforas tienen un profundo poder de invocación, inentendible para el profano (no hay que olvidar que la creencia en las brujas, y en el poder de sus palabras, estaba vigente en la Nueva Granada colonial, como muestra Uribe, 1987); por otro lado, el tiempo histórico de la sátira, en el que se quiere denunciar determinadas conductas de personas concretas. Este contraste resulta especialmente acusado al comparar los coros con las estrofas intermedias. En los coros, hay una mayor libertad para jugar con el ritmo de las palabras:

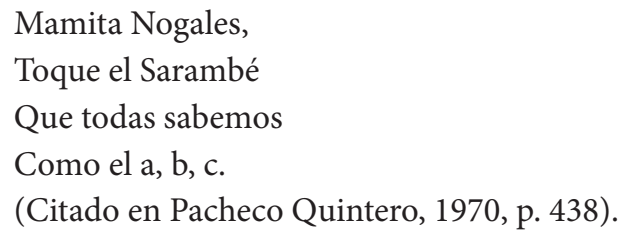

Encontramos aquí, por cierto, una interesante referencia al sarambé, ritmo afroamericano que crea un enlace entre la tradición española de los cantares de brujas y la cultura de origen africano. La cultura negra, por otro lado, no queda bien parada en la obra, puesto que se asocia a personajes malignos y emparentados con el Diablo.

Más explícita es la asociación que pretende establecer el poema entre las brujas y los oidores de la ciudad letrada, a quienes se invoca para que formen parte del siniestro cortejo (lo que recuerda a las "danzas de la muerte", tan frecuentes en la Edad Media europea). Estas invocaciones, que se realizan en las estrofas intermedias, entre las diversas jitanjáforas de los coros, tienen una clara intención satírica, lo que, en principio, no elimina del todo el estilo burlesco. Veamos, como muestra, las dos coplas dedicadas a Vicente Arámbulo, también conocido con el nombre de "Juan Largo", oidor y alcalde de la Corte:

Arámbulo es gato

Viejo de revés,

$\mathrm{Y}$ andar suele a gatas

De puro beber.

Centro de codicias

Su corazón es,

Malhayan sus ojos,

Malhaya él, amén.

(Citado en Pacheco Quintero, 1970, p. 440). 
En la primera estrofa, encontramos, además de la resemantización popular del término gato para hacer referencia a una persona taimada, un juego de palabras entre ser "gato" y andar "a gatas" por la adicción a la bebida. En la segunda copla, la acusación de codicia es más directa, pero en los dos últimos versos se utiliza una anáfora que recuerda la estructura de los romances de transmisión oral, y se asemeja a una maldición ritual apoyada en elementos del cristianismo ("amén"). La procedencia culta del anónimo autor no implicaría su desconocimiento de los recursos populares, que seguramente formaban parte del repertorio pasivo de los escritores de la cultura letrada colonial.

En este poema, por lo tanto, la hibridez de su doble origen, popular y letrado, se refleja en la continua tensión entre lo burlesco y lo satírico. En los coros, se marca el ritmo a través de una conocida melodía popular, y se libera el lenguaje de ataduras conceptuales; mientras que las estrofas intermedias introducen una denuncia que, de alguna manera, nos remite al mundo histórico de la seriedad empírica. A partir de este hecho, podríamos conjeturar que la poesía popular permite una mayor libertad para la jitanjáfora pura. Sin embargo, los poemas que estudiaremos a continuación, producidos desde lugares de enunciación exclusivamente letrados, complejizan esta conclusión. Al fin de cuentas, el juego puro con la materialidad del lenguaje no puede atribuirse a una sola lengua, época o clase social.

\section{El dislate culto: "Felicitación", de Francisco Antonio Rodríguez}

El siguiente poema, aunque escrito en el mismo contexto sociocultural por otro miembro de la élite criolla, en este caso de nombre conocido (Francisco Antonio Rodríguez), se sitúa en unas coordenadas muy distintas. A diferencia del anterior, no existe una clara inspiración popular en sus versos, escritos en pareados endecasílabos, aunque puedan presentarse convergencias en algunos recursos empleados. Tampoco existe una intención satírica, ni explícita ni camuflada.

De hecho, es evidente el tono festivo, ya desde el título: “Felicitación”. El poema está dedicado “al señor oidor doctor Nicolás Prieto y Dávila”, por su reciente nombramiento como oidor en la Audiencia de Quito. Uno de los descendientes de este oidor, José María Vergara y Vergara, rescata el poema y lo ofrece, más bien como curiosidad, en su conocida Historia. De sus palabras introductorias se desprende que el poema tenía carácter privado (o, como mucho, restringido a un grupo social muy cerrado) y carecía de pretensiones literarias.

Esta misma falta de pretensiones (en un autor que, al parecer, no escribió muchos más versos) podría explicar la libertad con que el poeta emplea el lenguaje, aunque también se puede asociar con el entorno de las tertulias literarias (se sabe que el autor frecuentaba la Eutropélica, fundada por Manuel del Socorro Rodríguez en la Santafé de finales del siglo XVIII). Recordemos que en este tipo de agrupaciones elitistas se gestó gran parte de la llamada "poesía festiva" (etiqueta que equivale a la de "poesía burlesca"), muy numerosa en el siglo XIX, y también presente en los años en los que escribe Rodríguez. Dos ejemplos casi contemporáneos son José Ángel Manrique ( $\mathrm{La}$ Tocaimada) y José Miguel Montalvo (Los ratones federados), ambos miembros habituales de la Tertulia del Buen Gusto. En este sentido, pareciera existir una relación entre lo burlesco y las nuevas formas de sociabilidad de la élite letrada.

El poema resulta representativo de lo que Alfonso Reyes llama dislate culto, que se produce por el absurdo de las relaciones establecidas entre las palabras, más que por los juegos acústicos en sí mismos. El carácter abierto de las categorías establecidas por Reyes para las jitanjáforas, sin embargo, se pone de manifiesto en algunos pasajes en los que Rodríguez crea neologismos y, de esa manera, practica la extrema fantasía de los significantes:

Me alegro, me realegro, me archi-alegro,

Me proto-alegro y me tatara-alegro.

(Citado en Vergara y Vergara, 1958, p. 96).

En cualquier caso, el principal procedimiento utilizado por Rodríguez es la exploración de la polisemia de ciertas palabras, creando relaciones conceptuales que escapan a la lógica habitual. En este sentido, destaca el uso de la palabra oidor. Como 
su amigo ha sido nombrado con este alto cargo de la burocracia colonial, el sujeto poético declara su fidelidad a los "oidores", y lo hace de esta manera:

Protesto ir a los sermones píos

en que nos diga el Padre: oyentes míos;

será el objeto de mi fe devota

todo auditor de la Romana Rota;

contra los sordos guardaré rencores

porque no son ni pueden ser oidores;

trataré con injurias infinitas

a cuantas cosas fueren inauditas.

(Citado en Vergara y Vergara, 1958, pp. 96-97).

La oposición creada entre el cargo de "oidor", por un lado, y las personas sordas y las cosas inauditas, por el otro, acerca estos versos al puro dislate, en semejanza a la tradición anglófona del "nonsense", con la diferencia de que aquí las transiciones se articulan a través de una palabra polisémica. Lo mismo sucede con la clasificación de los "oyentes" de una misa y el "auditor" de Rota (juez de un tribunal eclesiástico vaticano) como parte de un mismo grupo idolatrado. Esta apertura de sentidos por encima de la coherencia del lenguaje práctico recuerda algunas experiencias vanguardistas, tal y como subrayaba Samper Pizano (1965), pero debemos insistir en que se trata de un fenómeno de convergencia, y no de extraños pioneros.

El tema de la convergencia merece mayor detenimiento, puesto que no se reduce a los juegos disparatados con el lenguaje. En el poema de Rodríguez encontramos, al menos, tres características que lo relacionan con la estética contemporánea. Primero, la mezcla de registros lingüísticos: desde fórmulas protocolarias ("A Usía, señor, mi afecto inalterable") hasta lenguaje coloquial ("si mi alma hasta las cachas no se alegra"), e incluso invectivas que se acercan a lo vulgar ("una buena higa / para la beata que tal cosa diga"). Aunque no se puede hablar propiamente de polifonía, sí existe una heteroglosia que enriquece la frecuente univocidad del discurso letrado, lo que supone una contravención del "decoro" clásico.

Segundo, hallamos una análoga mixtura de referentes, desde la mitología grecolatina ("niégueme
Pitio Apolo sus concetos") hasta detalles de un realismo cotidiano ("la más dulce miel sobre buñuelos"). El desenfado con que se juntan los distintos referentes puede dar lugar a versos como los finales del poema: "Dada en Seguengue sobre aquel ribazo / que es el Vicegerente del Parnaso". Si el apelativo de "Atenas Suramericana" para Bogotá resulta discutible, la consideración de un ribazo de un pueblo del Cauca como "Vicegerente del Parnaso" solo puede interpretarse en un sentido irónico, o incluso paródico respecto a las convenciones literarias de su tiempo, lo que se logra - insistimos- por la superposición de elementos que, en teoría, son incompatibles entre sí.

Tercero, destacamos la ruptura de la falacia artística y la inclusión en el poema del autor ("pues todo puede ser en mi conciencia") y de sus reflexiones metapoéticas ("Vamos al caso, que estas digresiones / nada más hacen que aumentar renglones”). Esta autoconciencia literaria hace posible la parodia de las convenciones, como acabamos de ver, pero también la puesta en evidencia del propio poema como artefacto literario. En otras palabras, se podría incluso dudar de las alabanzas vertidas hacia el nuevo oidor, por el tono burlesco empleado. Creemos que el carácter del poema como documento privado entre amigos permite este tipo de licencias, a diferencia de las frecuentes loas recitadas, exhibidas o publicadas con motivo de la llegada de un Virrey, por citar un ejemplo habitual en la Colonia. ${ }^{4}$

Los tres rasgos que acabamos de apuntar resultan, en todo caso, sorprendentes en el contexto de la poesía canónica de su tiempo, puesto que, durante la Colonia (y más allá), en la Nueva Granada la alta cultura se ha identificado de forma casi exclusiva con el idealismo. Afirma Beltrán Almería (2016) que "como dogmáticos, los humanistas eran elitistas y defendían la pureza de la seriedad, en la vana esperanza de que la dignificación de lo serio

4 Con todo, los extremos de la poesía barroca también suelen convertir los poemas laudatorios en espectáculos de ingenio verbal. Según Beverley, se trataría de una estrategia consciente para remarcar la superioridad de la clase letrada. Quizás la comparación entre la seriedad barroca y la tradición burlesca sirva para poner en cuestión este habitual aserto, desde una perspectiva más lúdica y, en cierto sentido, más inocente. 
sirviera para alejar a la humanidad de sus registros animales y bárbaros (lo bajo)" (pp. 11-12). En el contexto neogranadino, en el que la ciudad letrada se superpone a una cultura considerada incivilizada y amenazante, esta frontera se radicaliza, por lo que es menos frecuente hallar la libertad burlesca de la metrópoli. Un ejemplo de la segunda mitad del siglo XVII es Francisco Álvarez de Velasco y Zorrilla, poeta santafereño que reutiliza los versos más serios de Quevedo sin repetir sus burlas.

El poema de Rodríguez, por lo tanto, muestra una cierta apertura de la ciudad letrada neogranadina, aunque limitada al contexto privado, como un divertimento de la clase alta. Sea como fuere, este tipo de poemas burlescos, así como aquellos emparentados con la cultura popular, suponen una de las escasas grietas por las que asoma el mundo sensitivo y la diversidad de hablas e imaginarios. Si tenemos en cuenta que esta mezcla es, precisamente, lo que caracteriza la modernidad literaria (Beltrán Almería, 2016), entenderemos mejor por qué el poema de Rodríguez puede recordarnos a la poesía contemporánea. La escritura en los márgenes, en ocasiones, muestra más coherencia con la modernidad que la tradición canónica en la que parece inscribirse. En otras palabras, y volviendo a Samper Pizano, poetas como León de Greiff, Luis Vidales o Jaime Jaramillo Escobar pueden sentirse más identificados con la "Felicitación" burlesca de Rodríguez que con la "Desesperación" de José Eusebio Caro o las "Horas de tinieblas" de Rafael Pombo.

\section{La extrema fantasía: "Para dar días o noches", de Francisco Javier Caro}

La tercera de las categorías establecidas por Alfonso Reyes (segunda en el ámbito de la literatura culta), es la extrema fantasía, definida como el trabajo radical con los valores acústicos de las palabras. Es decir, se trata de la jitanjáfora en su acepción más estricta. Como ejemplo de poema que emplea de forma destacada este recurso, hemos elegido "Para dar días o noches", de Francisco Javier Caro, autor que se destacaba por su frecuente cultivo de la décima, con intenciones satíricas (como las que escribiera contra los partidarios de la Independencia), o principalmente burlescas, como el poema que ahora comentamos.

Comencemos con un ejemplo de neologismos sin referente conceptual, creados por sus resonancias sonoras:

Primer verso pon: jaringo,

segundo pon: jilindango,

tercero pon: ringorrango,

cuarto pon: espingondingo.

(Citado en Vergara y Vergara, 1958, p. 123).

Aquí se evidencia la gratuidad de estas décimas, que el propio autor califica de "jocosas, / tan chuscas y salerosas / que no hubiera más que ver". Las palabras inventadas, sin embargo, no son las únicas que demuestran la prioridad otorgada a la materia acústica. Lo notaremos al copiar el final de esta misma décima, en el que se utilizan palabras existentes en los diccionarios:

[...] los otros seis con Domingo,

con fritada, con cebada,

chirlos mirlos y ensalada,

se llenan, como aquí ves,

$\mathrm{y}$ tienes en dos por tres

una décima fraguada.

(Citado en Vergara y Vergara, 1958, p. 123).

Parece obvio que palabras como Domingo, cebada o ensalada se emplean por sus valores fónicos (particularmente, el de la rima), y no por sus significados (aunque la palabra ensalada remite al género burlesco de la "ensalada de versos", que tuvo cultivadores tan destacados como Fernán González de Eslava).

Desde otra perspectiva, esta obra se puede adscribir a la tradición de poemas metapoéticos, de los cuales "Un soneto me manda hacer Violante" (Lope de Vega) es uno de los ejemplos más conocidos. Según Walters, se trata de una tendencia fácilmente identificable, en la que los poemas "rather than having to be about something, whether love, time or death, can be about itself: it can be its own subject and thus its own justification" (2002, p. 178). Estos poemas, al carecer de referentes extraliterarios, 
ofrecen más libertad para el trabajo con la materialidad de las palabras, y suelen ser una de las mejores excusas para realizar un alarde de ingenio.

Con todo, el poema de Caro explicita una justificación adicional: la sátira (a través de la parodia) de un mal poeta, como notaremos en los siguientes versos:

Cualquiera que considere

Los versos que escribiste

Dirá que los compusiste

A salga lo que saliere.

(Citado en Vergara y Vergara, 1958, p. 120).

La gratuidad del "salga lo que saliere" es, en cualquier caso, el principio que articula el poema del propio Caro, como se muestra desde su irónico título, "Para dar días o noches". En este sentido, creemos que la intención satírica es una simple cobertura para introducir lo que importa al poeta: el libre juego con los significantes a lo largo de doscientos versos. La presentación de la obra como el remedo de un poema chueco posibilita que el autor pueda desligarse de las convenciones de uso. En estas coordenadas lúdicas, se permiten los recursos que ya habíamos comentado en el análisis de Rodríguez: ruptura de la falacia artística (el autor aparece en el acto de componer sus versos), mezcla de referentes idealistas y cotidianos (de la "andaluzada" y la "panameñada" hasta las clásicas alusiones grecolatinas), $y$ uso de múltiples registros lingüísticos.

Como novedad, señalamos que en el poema de Caro no solo encontramos heteroglosia, sino incluso polifonía, es decir, incorporación dentro del poema de varias voces. En este sentido, "Para dar días o noches" se asemeja a la "Sátira" que Manuel de Lavardén escribiera en Buenos Aires por esas mismas fechas, en la que también se introduce la supuesta habla de diversos grupos sociales (Lagmanovich, 2002). En nuestro caso, las distintas voces se identifican con el uso de un determinado dialecto, como en el caso del gitano que cecea: "vaya, no se azuste uzía”. También, mediante la utilización de una lengua diferente:

El portugués se finchó,

y dijo al engaña-bobos:

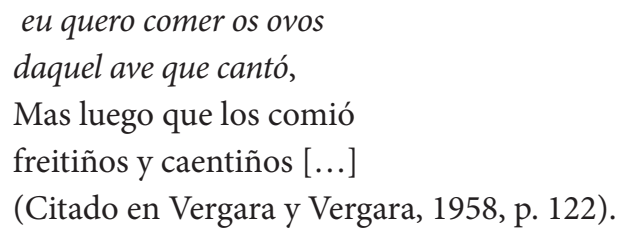

El objetivo de estos versos, claro está, no es la reproducción verosímil de la lengua portuguesa, sino el juego paródico con su materia acústica. Como recuerda Alfonso Reyes (2011), el uso de una lengua ajena es una vía frecuentemente utilizada para la creación de jitanjáforas (p. 37). Un ejemplo más radical, en esta misma época, sería el de la obra teatral "greco-chibcha" de Fernando de Orbea, $L a$ conquista de Santa Fé de Bogotá: aquí, la fingida reproducción de una lengua indígena da lugar a invenciones verbales puras.

Los versos de Caro que hemos reproducido más arriba vienen precedidos de una escena en la que un rebuzno, al desconocerse su referente emisor, se interpreta como gorjeo de pájaro: su sonoridad también podría haber sido resignificada a modo de jitanjáfora. ${ }^{5}$ En cualquier caso, el chiste se utiliza aquí como forma de ridiculizar al ingenuo portugués, que acaba comiendo los "huevos" del "ave" que rebuznó. El uso, con fines cómicos, del personaje extranjero (o, simplemente, diferente, como el caso de los negros en Quevedo, o del gitano en este mismo poema) era muy frecuente en la época, lo que hoy podría parecer inaceptable. Sin duda, tanto las formas del humor como sus límites cambian de forma notable a lo largo de la historia.

Por otro lado, parece oportuno resaltar cómo el poema de Caro reutiliza una de las formas simples que estudiara André Jolles (1974): el chiste. La historia del gitano, el burro y el portugués, que acabamos de comentar, pertenece a esta categoría. Existen, al menos, otros dos chistes en el poema: el de los dos pintores (tras la cháchara de uno, el otro afirma que, simplemente, "yo sé hacer / lo que habló

5 Es sugerente recordar que, desde los primeros días de la conquista, la realidad americana solía generar interpretaciones fantasiosas de los recién llegados. Con todo, el burro no era, desde luego, desconocido en Europa, sino más bien al contrario: posiblemente, los primeros burros criollos procedieron de la introducción de cuatro machos y dos hembras, por parte de Cristóbal Colón, en 1495. 
mi compañero") y el del ciego y el sordo (el ciego hablando de colores que el sordo, tras "escucharlos", reproduce sobre el lienzo). Esto resulta interesante por dos motivos: por un lado, porque supone la presencia de formas populares en el poema ( $y$, de esta manera, se tornan todavía más complejas las relaciones entre la tradición oral y la culta); y, además, porque los tres chistes señalan la distancia entre la realidad y las palabras que la designan. De hecho, la relación entre el significante y el significado es problematizada en todo poema burlesco, lo que nos permite escapar de los barrotes que trazan los sentidos unívocos.

Para completar este epígrafe, señalaremos muy brevemente un caso intermedio entre el "dislate culto" y la "extrema fantasía" en el uso del lenguaje. $\mathrm{Su}$ autor también pertenece a la Nueva Granada del siglo XVIII: Francisco Antonio Vélez Ladrón de Guevara (Santafé de Bogotá, 1721-1781). El poema "Describe largamente un paseo de varias madamas y otras personas" comienza presentando un sujeto poético encerrado en su biblioteca y hastiado por las demasiadas lecturas. El estado de confusión en que se halla este sujeto se expresa de forma bastante original:

Y por librarme de libros, los fui poniendo en su estante quedando yo hecho estantillo, sin que me agradezcan Gómez, González ni Fermocinos, volúmenes, inforciatos, leyes, ni legisperitos, gestos al digesto haciendo, teniendo a Baldo baldío, matándome los Matienzos [...] (1992, p. 138).

Aquí encontramos la reutilización de los referentes librescos en su materialidad acústica, creando asociaciones inauditas entre algunos nombres de obras y autores, por un lado, y, por el otro, lexemas evocados por su semejanza fónica (El "Baldo" con baldío; Juan de Matienzo con matar). En este caso, existe una fructífera combinación de los dos tipos de jitanjáforas cultas establecidas por Reyes, ya que el juego con la materia acústica lleva a trazar asociaciones absurdas. Los estados límite en que se produce un desarreglo de los sentidos (en este caso, por el mucho leer) propician la escritura delirante: no podemos dejar de notar las convergencias con el propio Quijote. En definitiva, la libertad de lo burlesco resulta propicia para representar cierto grado de alteración mental (no en vano, varias formas de la locura generan un uso particular del lenguaje).

En otro orden de cosas, el ejemplo de Vélez Ladrón se diferencia de los poemas de Rodríguez y de Caro en el hecho de localizar el tono burlesco en un fragmento que, por este motivo, se diferencia de los que siguen. En efecto, se narra a continuación una serie de pasajes de corte rococó en el que aparecen algunos elementos costumbristas, incluyendo una descripción del salto del Tequendama, en las afueras de Bogotá. El poema confirma, por lo tanto, que lo burlesco puede aparecer de forma aislada en una obra situada, por lo general, en el ámbito de lo serio. En estos casos, como sucede de forma más significativa en las Elegías de Castellanos, el enfrentamiento de dos estéticas (la seriedad y la risa) supone también la confrontación de dos visiones del mundo.

\section{Conclusión}

La poesía burlesca constituye una tradición doblemente marginal, a pesar de su vitalidad y de sus convergencias con la poesía moderna. El primer motivo de marginación es su inserción en el ámbito de la risa más "insignificante", ya que, a diferencia de la sátira, lo burlesco no se justifica por tratar significados "importantes", como la reprensión de vicios. El segundo motivo está relacionado, más bien, con la crítica literaria, puesto que, como consecuencia de lo anterior, es difícil analizar lo burlesco a modo de "documento" cultural. Ni siquiera el formalismo podría encontrar una adecuada fuente de información en este tipo de poemas, ya que resulta escasa, e incluso nula, su evolución formal.

Desde la introducción, este artículo se ha insertado en la línea de revalorización crítica de la poesía burlesca. Los pocos teóricos que se han acercado a este tipo de obras, como el propio Alfonso Reyes, 
han subrayado el carácter periférico, e incluso heterodoxo, de esta vertiente. Sin salirnos del contexto de la Hispanoamérica colonial, Lasarte aprecia este tipo de obras porque "permite suspender el orden de la cultura oficial” (2009, p. 270). En efecto, los poemas que hemos estudiado se distancian del idealismo habitual en la ciudad letrada y generan pliegues por los que se introducen distintos imaginarios $y$ registros lingüísticos.

Desde una perspectiva más filosófica, José María Valverde (2008) exalta el trabajo con la materialidad del lenguaje, puesto que "estar del lado de la palabra es estar del lado de los pobres, de lo pobre, de lo concreto y lo de todos, y es estar contra el despotismo de arriba, cuyo arquetipo está en el idealismo del aristócrata Platón" (p. 11). En efecto, apostar por el lenguaje, por el sonido concreto, de alguna manera supone una ruptura con el mundo de la seriedad idealista. Todo poema burlesco, cuando menos, pone en cuestión la supuesta relación entre las palabras y los conceptos que pretenden representar, como vimos más arriba. Y este cuestionamiento es una de las principales tareas que puede asumir la literatura.

Ahora bien, es necesario discutir los límites de este supuesto carácter subversivo de la poesía burlesca. Para ello, debemos separarnos del contexto contemporáneo, que entiende los procedimientos análogos de la literatura del siglo xx como revolucionarios. Primero, no podemos situar la poesía burlesca en un esquema de evolución (y, por lo tanto, de revolución), ya que sus procedimientos se utilizan en múltiples culturas desde tiempos inmemoriales, como muestran los ejemplos de la cultura popular. Lo burlesco, por lo tanto, es una vertiente tradicional, en lugar de una innovación de ciertos autores o épocas inconformes.

Segundo, el lugar de enunciación de los textos estudiados revela una posición de privilegio, respecto a otras culturas presentes en la Nueva Granada (especialmente los indígenas y los negros) y respecto a las periferias hispanas de la ciudad letrada. En efecto, los autores son, en todos los casos analizados, miembros de la élite criolla, que conciben sus obras como divertimento y demostración de agudeza ante sus pares. Los poemas de Rodríguez y de Caro, dirigidos de forma explícita a otros colegas, lo demuestran. También se conoce el contexto de producción de Vélez Ladrón de Guevara: se trataba de obras de circulación exclusiva entre los cortesanos cercanos al Virrey. En cuanto a las "Coplas del baile de las brujas", muestran un posible intento de traspasar las fronteras de la ciudad letrada, pero solo para fortalecer a uno de los bandos en un conflicto interno de la élite.

Es decir, la peculiaridad de los textos analizados no nos permite interpretarlos como subversivos en su propio contexto de recepción, ni tampoco como novedosos, pues se insertan en una tradición mucho más extensa que la propia poesía culta. Con todo, es justo reconocer su diferencia respecto a la poesía habitualmente practicada en la Colonia: la jitanjáfora rítmica, al tiempo que invectiva, de las "Coplas del baile de las brujas"; el dislate que crea sentidos inesperados en Francisco Antonio Rodríguez; el puro disfrute de los sonidos y los chistes populares en Francisco Javier Caro; el desarreglo de los sentidos de Vélez Ladrón; pueden todavía ser plenamente disfrutados por los lectores $y$, desde luego, deben formar parte de cualquier panorama de la literatura neogranadina, hasta ahora limitada a obras de seriedad idealista.

En definitiva, el aporte del presente artículo se sitúa en una posición paradójica: al tiempo que intenta desvelar una tradición ocultada en la poesía colonial, la conecta con manifestaciones de toda lengua y momento, incluso de la vida cotidiana (recordemos, de nuevo, las rimas infantiles), lo que parece desmentir su carácter único. En efecto, a veces resulta necesaria la revaloración de lo común, de lo más evidente. Lo burlesco es parte esencial del homo ludens que somos, lo que no puede dejar de manifestarse en nuestras producciones verbales, orales y escritas, desde el joven de la barriada popular de hoy hasta el ilustre oidor de la Audiencia de Quito. Debemos recordarlo cuando intentemos ofrecer una imagen completa de la creación literaria. 


\section{Referencias}

Arellano, I. (2006). Las máscaras de Demócrito: en torno a la risa en el Siglo de Oro. En I. Arellano y V. Roncero (Eds.). Demócrito áureo. Los códigos de la risa en el Siglo de Oro (pp. 329-359). Sevilla: Renacimiento.

Beltrán Almería, L. (2016). Estética de la risa. México: Ficticia.

Beverley, J. R. (1992). On the concept of the Spanish Literary Baroque. Culture and Control in CounterReformation Spain (pp. 216-230). Minnesota: University Press.

Cacho Casal, R. (2007). El ingenio del arte: introducción a la poesía burlesca del Siglo de Oro. Criticón, 100, 9-26.

Éluard, P. (1926). Fantrasies. La Révolution Surréaliste, 6, 2-3.

Jolles, A. (1974). Las formas simples. Santiago de Chile: Ed. Universitaria.

Lagmanovich, D. (2002). Nuevas notas sobre la Sátira (1786) de Manuel José de Lavardén. Revista Chilena de Literatura, 60, 101-109.

Lasarte, P. (2009). Mateo Rosas de Oquendo: la sátira y el carnaval. En I. Arellano y A. Lorente Medina (eds.). Poesía satírica y burlesca en la Hispanoamérica colonial (pp. 266-272). Madrid: Iberoamericana.

Martínez Pérez, A. (1987). La poesía medieval francesa del "non-sens": fatrasie y géneros análogos. Murcia: Universidad de Murcia.

Orbea, F. de (1950). Comedia nueva: la conquista de Santa Fé de Bogotá. Bogotá: Ministerio de Educación de Colombia.
Orwell, G. (2016). Epílogo. En E. Lear. Todo disparates $y$ otros tantos dislates (pp. 189-199). Salamanca: El Gallo de Oro.

Otero Muñoz, G. (1928). La literatura colonial y popular de Colombia. La Paz: Imprenta Artística.

Pacheco Quintero, J. (1970). Antología de la poesía en Colombia (vol. 1). Bogotá: Instituto Caro y Cuervo.

Reyes, A. (2011). El libro de las jitanjáforas. México: Bonilla Artigas Editores.

Samper Pizano, D. (1965). Un De Greiff del siglo XVIII. Boletín Cultural y Bibliográfico, 8(01), 64-72.

Uribe, M. V. (1987). Los ocho pasos de la muerte del alma: la inquisición en Cartagena de Indias. Boletín Cultural y Bibliográfico, 24(13), 29-39.

Valverde, J. M. (2008). Vida y muerte de las ideas. Madrid: Ariel.

Vélez Ladrón de Guevara, F. A. (1992). Poesías. Bogotá: Kelly.

Vergara y Vergara, J. M. (1958). Historia de la literatura en Nueva Granada. Desde la Conquista hasta la Independencia (1538-1820) (vol. 2). Bogotá: Biblioteca de la Presidencia de Colombia.

Walters, G. D. (2002). The Cambridge Introduction to Spanish Poetry. Cambridge: University Press.

Ynduráin, F. (1974). Para una función lúdica en el lenguaje. En Doce ensayos sobre el Lenguaje (pp. 215227). Madrid: Fundación Juan March. 